\title{
GHG emissions, GDP growth and the Kyoto Protocol: A revisit of Environmental Kuznets Curve hypothesis
}

\author{
Wei Ming Huang ${ }^{\mathrm{a}}$, Grace W.M. Lee ${ }^{\mathrm{a}, *}$, Chih Cheng Wu ${ }^{\mathrm{b}}$ \\ ${ }^{a}$ Graduate Institute of Environmental Engineering, National Taiwan University, 71, Chou-Shan Road, Taipei 106, Taiwan, ROC \\ ${ }^{\mathrm{b}}$ Energy \& Air Pollution Control Section, New Materials R\&D Department, China Steel Corporation, 1, Chung-Kang Road, \\ Siaogang District, Kaohsiung 81233, Taiwan, ROC
}

Received 7 June 2007; accepted 13 August 2007

Available online 22 October 2007

\begin{abstract}
The Kyoto Protocol attempts through political negotiations to guide participating industrialized countries' greenhouse gas (GHG) emissions from a positive growing trend, to reach a peak point (or turning point), and then be reduced to a negative growth. That means the relationship between decreasing GHG emissions and economic growth may be described by an inverted-U curve (or called a bellshaped curve), which is consistent with the concept of the Environmental Kuznets Curve (EKC) hypothesis.

This research observed that the economic development and GHG emissions in Economies in Transition (EITs) exhibit a hockey-stick curve trend (or called quasi-L-shape curve), that also generates a lot of "hot air" which is significant to the implementation of the Kyoto Protocol. In addition, through the analysis of single-country time series data and GDP data, this research demonstrated that statistical data for most of the Annex II countries do not possess evidence that supports the EKC hypothesis for GHG emissions. The results from this study also indicated that the 38 industrialized countries are unable to meet their targets under the Kyoto Protocol within the specified time period, which are probably caused by the econometric method's inability to predict accurately the extents and development of innovative technologies and Clean Development Mechanism (CDM) projects. If the international community truly wants to reduce the GHG emissions, the effectiveness of the existing international framework for emissions reduction needs to be reconsidered seriously, and the global cooperation mechanism also needs to be greatly enhanced.
\end{abstract}

(C) 2007 Elsevier Ltd. All rights reserved.

Keywords: EKC hypothesis; Kyoto Protocol; Greenhouse gas

\section{Introduction}

The relationship between economic development and environmental protection has long been a subject of constant concern and research. Whether economic development creates problems for environmental protection or improves environmental quality may be studied through the use of econometric methods. For past researches, the most often adopted methodology for such analyses is the Environmental Kuznets Curve (EKC) hypothesis, which hypothesizes that the environmental quality deteriorates with economic growth, and that their relationship can be

\footnotetext{
${ }^{*}$ Corresponding author. Tel.: + 886223633249 ; fax: + 886223633249 .

E-mail address: gracelee@ntu.edu.tw (G.W.M. Lee).
}

expressed in the shape of an inverted-U or bell-shaped curve.

The EKC hypothesis was first proposed by Dr. Simon Kuznets, winner of the Nobel Prize in Economics in 1971. Dr. Kuznets believed that economic development and inequality in income distribution can be expressed by an inverted-U curve relationship, which can be verified both theoretically and empirically. Meadows et al. (1972) also mirrored Dr. Kuznets's hypothesis in their Limits to Growth hypothesis, and proposed that as higher economic activities require more inputs of energy and materials, they will in turn create more wastes and undesired byproducts that will then degrade the environmental quality.

In the World Development Report published by the World Bank in 1992, the subject of environmental deterioration versus economic development was first 
emphasized and studied in detail. The report stated that some indicators of environmental deterioration, such as carbon dioxide emissions and generation of urban waste, will increasingly worsen with the progress of economic development. However, some environmental indicators, such as lack of safe drinking water and urban sanitary conditions, will improve through economic growth, meaning that economic development may also improve environmental quality. In addition, many environmental indicators, such as emissions of sulfuric oxides and nitric oxides, may show an inverted-U curve relationship with economic growth. At the beginning of economic development, the environmental quality will deteriorate with economic growth. However, after reaching a peak point (turning point), the environmental quality may improve with subsequent economic growth.

Munasinghe (1995) and Panayotou (1997, 2003) proposed that if such an EKC relationship also exists in the historical data of mixed nations, then developing countries may learn from the experiences of developed countries and thus avoid their past mistakes. In other words, developing countries may base on the past experiences of developed countries and remove environmentally harmful subsidies, in order to avoid deterioration of environmental quality beyond the ecological threshold (as shown in Fig. 1).

Furthermore, past studies of environmental quality mostly focused on air pollution indicators (e.g., $\mathrm{SO}_{x}$, suspended particles and greenhouse gases (GHGs)) and water pollution indicators (e.g., dissolved oxygen in rivers, BOD and Escherichia coli). However, other researchers (Shafik, 1994; Grossman and Krueger, 1995) have also looked at issues such as areas of deforestation, urban waste generation and ratio of clean water supplies, which show that this subject may be studied using a multi-faceted approach.

\section{Literature review}

In the past, carbon dioxide emissions were treated as harmless byproducts of clean or efficient burning process and not given appropriate attention. However, after the 1997 UNFCCC Kyoto meeting, carbon dioxide emissions

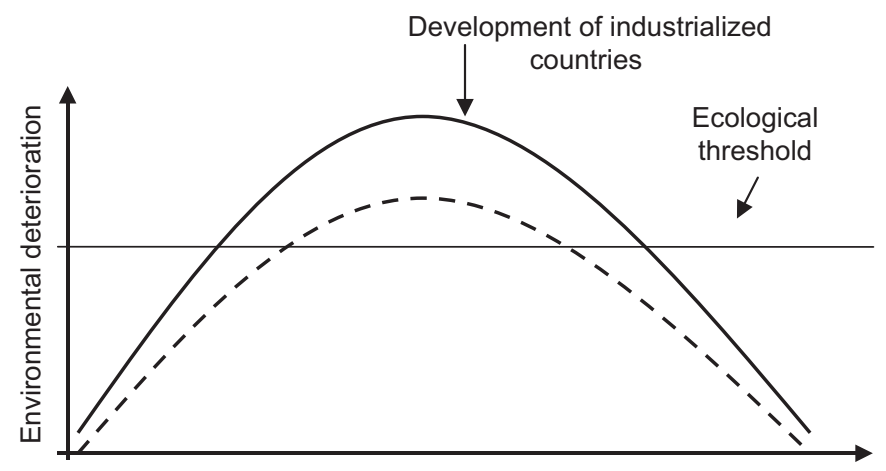

Per capita income

Fig. 1. Application of the Environmental Kuznets Curve hypothesis. have become a focus of international attention. Thus, the understanding of whether carbon dioxide emission reduction will become a natural byproduct of economic development, especially in the area of energy consumption improvement, is beneficial to the development of emissions reduction strategies.

During the discussion of EKC, the debate on the issue of GHGs (especially carbon dioxide) is often contentious, as vastly different opinions were presented in past research. Some researchers concluded that there is no EKC relationship with carbon dioxide, while others pointed to the existence of explicit turning point (Holtz-Eakin and Selden, 1995; Moomaw and Unruh, 1997; Schmalensee et al., 1998; Dijkgraaf and Vollebergh, 2001).

Holtz-Eakin and Selden (1995) may be the first group to study the EKC relationship with carbon dioxide based on the econometric method. They used 13 high-income countries' 1951-1986 statistics as input data for their research. During their analysis of quadratic relationship, whenever the per capita income reached US\$35,428, a turning point will occur; for the logarithm function relationship study, a turning point will only occur at a very high per capita income of US\$8,000,000. They believed that the relationship between carbon dioxide and per capita GDP is the same as with other pollutant emissions, but the turning point will occur at a much higher (or even out of sample) per capita income range. Their conclusion implied that mitigation of global warming can only be achieved through international cooperation.

Moomaw and Unruh (1997) selected 16 OECD member countries (Austria, Belgium, Canada, Denmark, Finland, France, West Germany, Iceland, Italy, Japan, Luxemburg, Netherlands, Sweden, Switzerland, UK and US) as the subjects of their study, and analyzed the carbon dioxide intensity and GDP through graphic presentation. Based on their graphic analysis, the authors concluded that during 1974-1975, due to the impact on energy structure caused by the oil crisis, most of the studied countries exhibited some inverted-U-curve trend that peaked at around 1970-1980. Furthermore, after applying the cubic EKC model to the 16 countries, the authors observed that all estimations are statistically significant and exhibited an $\mathrm{N}$ type linear relationship, with the first turning point at US $\$ 12,813$ and the second turning point at US\$18,333. This result is lower than the US\$35,428 as predicted in the Holtz-Eakin and Selden (1995) study.

Roberts and Grimes (1997) applied carbon dioxide intensity to the study of EKC hypothesis and used the emissions data from 147 countries as input data. After taking the logarithm form of carbon dioxide intensity and GDP, the authors applied a scattering graphic examination of the 25-year period data (with a 5-year interval at 1965 , 1970, 1975, 1980, 1985 and 1990) and used the OLS method to check for curve linearity relationship. The authors then divided the studied countries into three groups based on their per capita incomes. It was observed that for high-income countries, the energy efficiency was 
improved after the 1973 and 1979 oil crises; however, there were no significant improvement for the low- or midincome countries. The authors' conclusion was that the EKC relationship for high-income countries did exist as represented by the efficiency improvement. However, for mid- or low-income countries, only environmental deterioration was observed. The authors inferred that as highincome countries moved their high-pollution industries to developing countries, the pollution-haven hypothesis have been validated by many researchers, and that an international environmental standard and promotion mechanism is required.

Schmalensee et al. (1998) observed and divided 141 countries into two groups: developing countries (such as South Korea and India) and developed countries (such as US and Japan), and concluded that as per capita income increased, some countries (such as US) will exhibit a decrease in carbon dioxide emissions reduction, resulting in an inverted-U curve.

Dijkgraaf and Vollebergh (2001) re-analyzed the results of the Schmalensee, et al. (1998) study, and concluded that their cross-country data homogeneity assumption was problematic and that no such EKC exists for carbon dioxide emissions.

As most past research was focused on cross-sectional global data, there were relatively few studies on a single country. Most research on the EKC relationship in single countries was conducted after 1997 by researchers such as Sun (1999), Roca and Alcantara (2001) and Friedl and Getzner (2003).

Sun (1999) proposed the peak theory for energy intensity and theorized that at the beginning of industrial development, the energy intensity of a country will rise quickly, then peak and decrease subsequently. The peaking times are 1880s for UK, and 1920s for US and Germany, 1929 for France and 1970s for Japan. These turning and peaking phenomena indicate that these countries are undergoing industrial re-structuring into high value-added industries.

Roca and Alcantara (2001) studied the energy intensity, carbon dioxide emissions and EKC relationship for Spain, and graphed the energy intensity and unit energy carbon dioxide emission based on time series. As opposed to the conclusion of Sun (1999), they observed no consistency and thus concluded that the energy intensity for Spain during the past 25 years did not decrease gradually.

Friedl and Getzner (2003) believed that both linear and quadratic models do not apply to the case for Austria, which can be more appropriately expressed by the cubic expression. It showed that during the period of 1960-1999, the GDP and carbon dioxide emissions can be expressed with a N-type (third-order) expression. The study concluded that carbon dioxide emissions can grow rapidly with GDP and will not show structural changes for some variables. Also, if effective carbon dioxide emissions were to be achieved, energy prices should be changed through policy and that carbon tax (eco-tax) can be used as an effective means.

\section{Subjects and data of analysis}

The 1992 United Nations Framework Convention on Climate Change (UNFCCC) requires 41 countries and European Union to fulfill their responsibilities to reduce GHG emissions. These countries can be divided into two groups (Annex II countries and Economies in Transition (EITs)) as listed in Table 1. The abbreviations of country name commonly used are also provided in the same table.

Under the UNFCCC, the Kyoto Protocol was adopted in 1997 and requires 38 Annex I countries and European Union to reduce their emissions to $5.2 \%$ below the 1990 emissions levels during the 2008-2012 period. The Kyoto Protocol regulates six types of GHGs: $\mathrm{CO}_{2}, \mathrm{CH}_{4}, \mathrm{~N}_{2} \mathrm{O}$, PFCs, HFCs and $\mathrm{SF}_{6}$.

Past studies on the relationship between GHGs and economy were mostly based on information from the International Energy Agency (IEA) on carbon dioxide emissions from fuel combustion process, and have little discussion on other GHGs. However, the Kyoto Protocol regulates six types of GHGs, not just carbon dioxide. Therefore, the GHGs analyzed in this research is based on the "Key GHG Data" released by the UNFCCC in 2005, which covered the data from the 1990-2003 National Communications and annual GHG emissions statistical data that have gone through in-depth reviews by relevant experts. As for the population and GDP numbers, they are

Table 1

Annex I parties categories and abbreviations

\begin{tabular}{lllll}
\hline Annex II Parties & & \multicolumn{2}{l}{ Economies in Transition, } & Others \\
& & EIT & & \\
\hline Australia & AUS & Belarus & BLR & Liechtenstein \\
Austria & AUT & Bulgaria & BGR & Monaco \\
Belgium & BEL & Croatia & HRV & Turkey \\
Canada & CAN & Czech & CSK & \\
& & Republic & & \\
Denmark & DNK & Estonia & EST & \\
Finland & FIN & Hungary & HUN & \\
France & FRA & Latvia & LVA & \\
Germany & DEU & Lithuania & LTU & \\
Greece & GRC & Poland & POL & \\
Iceland & ISL & Romania & ROM & \\
Ireland & IRL & Russia & RUS & \\
Italy & ITA & Slovak & SVK & \\
& & Republic & SVN & \\
Japan & JPN & Slovenia & UKR & \\
Luxembourg & LUX & Ukraine & & \\
Netherlands & NLD & & \\
New Zealand & NZL & & \\
Norway & NOR & & \\
Portugal & PRT & & \\
Spain & ESP & & \\
Sweden & SWE & & \\
Switzerland & CHE & & \\
United & UK & & \\
Kingdom & & & \\
United States & USA & & \\
\hline
\end{tabular}


based on the $\mathrm{CO}_{2}$ Emissions from Fuel Combustion 1971-2003 (IEA, 2005).

The most significant aspect of the countries with EITs is that their economic structures are undergoing transformation, and the largest changes are occurring in the collapses of their industrial sectors that resulted in a great decline of their GDPs. EITs suffered through unprecedented economic turmoil during the period of 1988-1991, which saw the collapses of their traditional export market, as well as decreasing domestic consumption and industrial production and thus significant decline of GDPs. As a result, two economic features are characteristic of the EITs. The first is that the collapsed economic growth resulted in greatly reduced carbon dioxide emissions. For example, during the 1988-1991 period, the GDP of Poland decreased by $20 \%$ and carbon dioxide emissions also reduced $22 \%$. The second feature is the high proportion of industrial production, which resulted in a high energy consumption per unit GDP, and affects EITs' ability to seek a suitable, efficient and highly cost-effective climate change policy and measures (Simeonova, 1997).

Based on national statistics, Annex II countries typically have a per capita GDP of over US\$10,000 and can be classified as high-income countries. In accordance with Article 4.5 of the UNFCCC, Annex II countries should bear the responsibilities for helping, promoting and financially assisting affected countries in dealing with the impacts of climate change. In addition, 22 Annex II countries are authorized to become purchasers of emissions quota, and under the Kyoto Protocol, the Assigned Amount Units assigned to the Annex II countries are roughly 2.2 times those of the EITs (Missfeldt and Haites, 2002).

As the GHG emissions data and GDP for Monaco and Liechtenstein are unavailable publicly, they are thus excluded from this research, which is consistent with the Missfeldt and Haites (2002) study. Furthermore, although Turkey is an Annex I country, it has not submitted new GHG emissions inventory and is not one of the Annex B parties in the Kyoto Protocol. Thus it is also excluded from the scope of this research.

\section{Methodology}

First, this research plotted the per capita GDP as $x$-axis and annual per capita GHG emissions as $y$-axis to demonstrate the different developing trends among EITs and Annex II countries.

Secondly, in order to study whether the EKC hypothesis does apply, this research employed the econometric method for analysis, so as to understand whether related values are of statistical significance and can be used to validate the hypothesis. Three types of empirical methods are typically used in the analysis of the EKC hypothesis (Selden and Song, 1994; Grossman and Krueger, 1995; Holtz-Eakin and Selden, 1995; Friedl and Getzner, 2002), and they are in log-linear, quadratic and cubic forms. The relationship between individual environmental quality indicator and per capita income may be studied by using curve fitting. As for the other factors such as time, regional characteristics and technical factors, they may be expressed as external variables in the following equations:

$Q_{t}=a_{0}+a_{1} \ln Y_{t}+G_{t}+\varepsilon_{t}$,

$\left\{\begin{array}{l}Q_{t}=a_{0}+a_{1} Y_{t}+a_{2} Y_{t}^{2}+G_{t}+\varepsilon_{t}, \\ \ln Q_{t}=a_{0}+a_{1} \ln Y_{t}+a_{2}\left(\ln Y_{t}\right)^{2}+G_{t}+\varepsilon_{t},\end{array}\right.$

$\left\{\begin{array}{l}Q_{t}=a_{0}+a_{1} Y_{t}+a_{2} Y_{t}^{2}+a_{3} Y_{t}^{3}+G_{t}+\varepsilon_{t}, \\ \ln Q_{t}=a_{0}+a_{1} \ln Y_{t}+a_{2}\left(\ln Y_{t}\right)^{2}+a_{3}\left(\ln Y_{t}\right)^{3}+G_{t}+\varepsilon_{t} .\end{array}\right.$

This research defines $Q$ as the per capita GHG emission, $Y$ as per capita annual averaged GDP, $t$ as time, $G$ as the external variable (this research adopts the most simple configuration, with no newly added external variables, and directly observes per capita GHG emissions and per capita GDP), $\varepsilon$ as the stochastic error and $a$ as the coefficient (also called marginal propensity to emit) (Sun, 1999). Of the three aforementioned equation sets, the second set (2) is most often used, meaning that the consumption of environmental quality (pollution releases) will first increase with increasing GDP and then decrease, which forms the so-called Environmental Kuznets Curve. The conditions for this to occur are for estimated coefficient $a_{1}>0, a_{2}<0$, its turning point is $-a_{1} / 2 a_{2}$.

When air pollutants were used as environmental indicators, past researchers have already shown the trend to replace ambient concentration with the amount of emissions. And when the emissions are used in EKC studies, the resultant turning points for emissions are higher than those obtained from using concentration (Stern, 1998).

However, the GHG emissions data for some countries are incomplete (shown as zero). And if the emissions are treated as zero, it is meaningless to conduct logarithm analysis. Thus, this research excluded the use of logarithm analysis and instead focused on the commonly used econometric method for analysis, with the major focus on the quadratic curve fitting and the significance of $R^{2}$ value, as indicators for whether the hypothesis can be validated.

\section{Results}

\subsection{EITs' hockey-stick-curve trend}

The economic development for the EITs exhibits a hockey-stick-curve trend (or called quasi-L-shape curve) (see Fig. 2), indicating that the collapsed economy during the early 1990s not only have a great impact on the industry but also generates a lot of "hot air", which is significant to the implementation of the Kyoto Protocol 


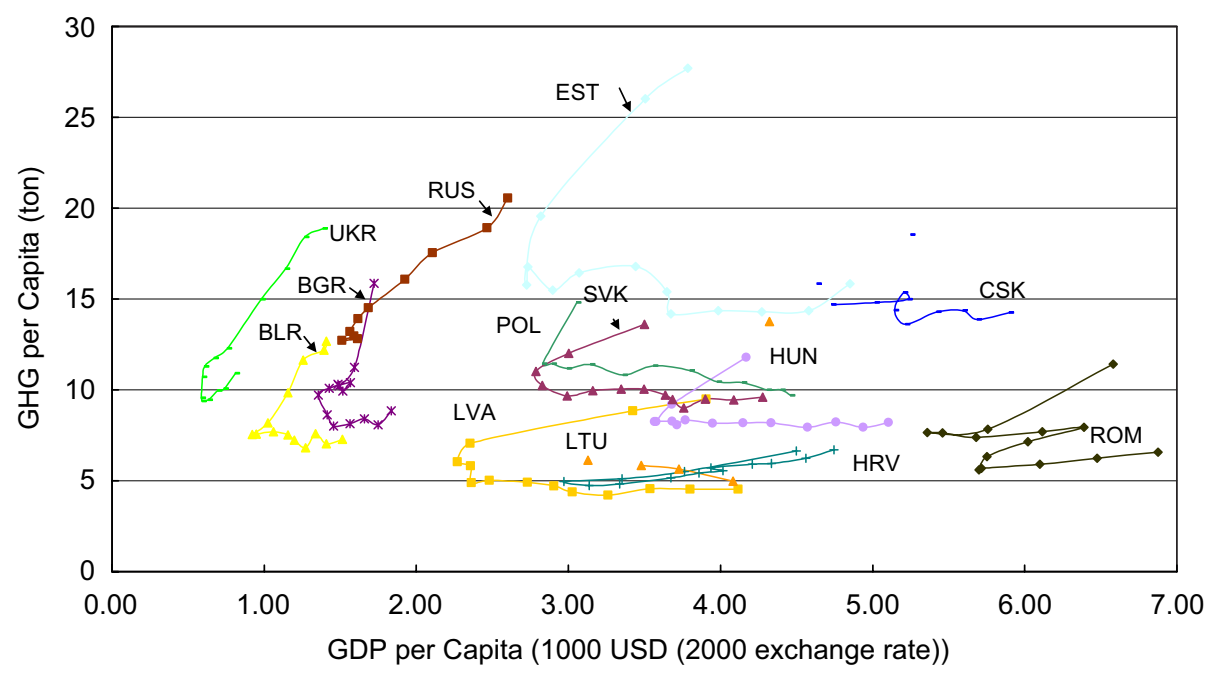

Fig. 2. Relationship between per capita GHG emission and per capita GDP in EIT countries (1990-2003).

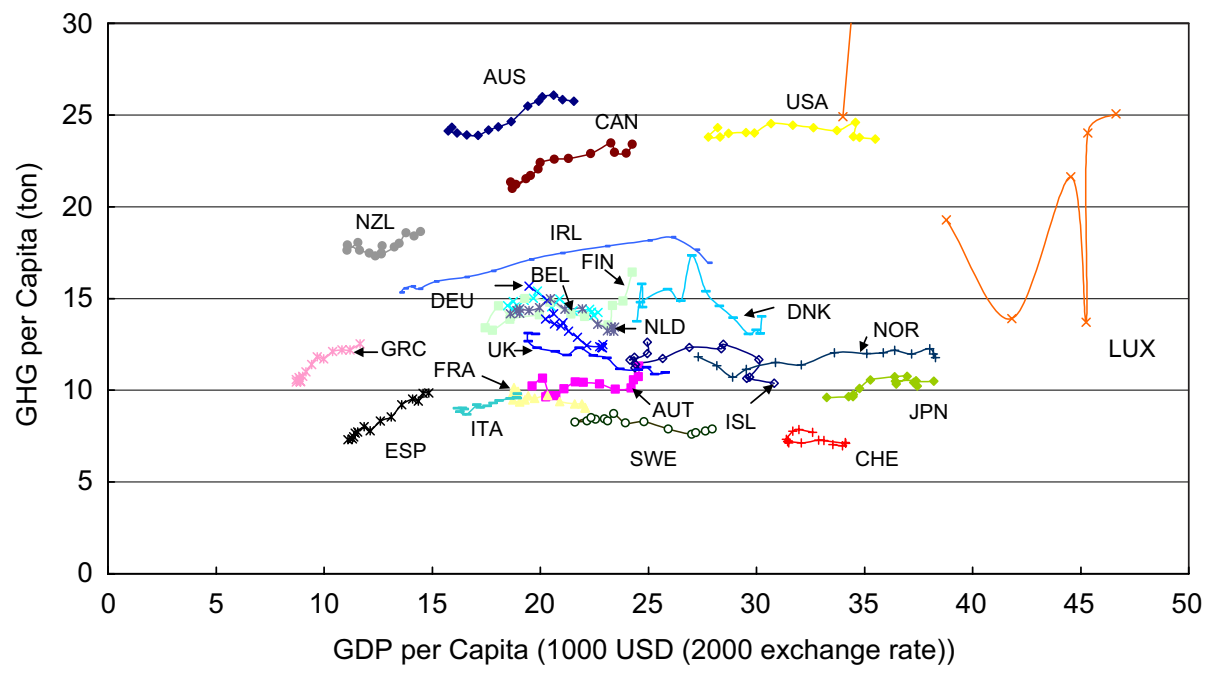

Fig. 3. Relationship between per capita GHG emission and per capita GDP in Annex II countries (1990-2003).

(Klepper and Peterson, 2002; Klepper et al., 2003). As for Annex II countries, different trends can be observed.

For EITs, the hockey-stick-curve trend has seldom been mentioned in past research. EITs' GHG emissions rebound quickly with the recovery of their economies. Duic et al. (2005) pointed out that even though the GHG emissions of Croatia is below the Kyoto target before 2005, its emissions will exceed the Kyoto goal after 2012 with GDP growth. Therefore, if EITs wish to continue reducing their GHG emissions, additional reduction measures would be required. The "hot air" generated in the early 1990s can only be used to meet the Kyoto goals for the 2008-2012 commitment period and not for subsequent commitment periods.

Based on the observed trends from available data, it is unlikely for the EITs to validate the EKC hypothesis, and therefore the use of econometric analysis may be excluded.

\subsection{Annex II countries: EKC hypothesis testing}

As for the Annex II countries, various increasing or decreasing trends may be observed (see Fig. 3). The initial observations show that 10 countries show an increasing GHG emissions to GDP relationship, while another 11 counties show the decreasing trend relationship, with the curve for Luxembourg being the most unique. Luxembourg's per capita GHG emissions show a great variation in recent years based on different sources, e.g., IEA (2005) statistics, emissions data from the 2005 annual inventory and 2001, 2002, 2003, 2004 data and some 1996 data in the first National Communication.

The results of econometric analysis may be discussed from the perspectives of significance of per capita GDP relative to per capita GHG emissions, $R^{2}$ and adjusted $R^{2}$. The number of $R^{2}$ is an indication of how good the 
regression fitting is. The higher the $R^{2}$ value, the better the explanatory power for curve fitting. In addition, this research used the $t$-statistic to examine the effect of independent variable (per capita GDP) on dependent variable (GHG emissions per capita). This research also used the symbols of ***, ** and * to indicate the significance of $1 \%, 5 \%$ and $10 \%$ probability statistics. When the $t$-statistic occurs at a probability of less than
$10 \%$, it is an indication that this coefficient has less explanatory power. The results for the statistical analysis are explained below and shown in Table 2:

1. Fitting the EKC curve and $R^{2}$ values statistically significant: Belgium, Canada, Greece, Iceland, Japan, Netherlands and the US, of which only Canada, Greece and Netherlands have an $R^{2}$ value close to or higher

Table 2

Analysis of environmental Kuznets Curve Hypothesis for GHG emissions and GDP of Annex II countries

\begin{tabular}{|c|c|c|c|c|c|c|}
\hline \multirow[t]{2}{*}{ Country } & \multirow[t]{2}{*}{ Curve trend } & \multicolumn{5}{|c|}{ Environmental Kuznets Curve testing } \\
\hline & & Constant & $Y$ & $\mathrm{Y}^{2}$ & $R^{2}$ & Adjusted $R^{2}$ \\
\hline AUS & Upwards & $\begin{array}{l}27.86219 * * \\
(2.453864)\end{array}$ & $\begin{array}{c}-0.730666 \\
(-0.590825)\end{array}$ & $\begin{array}{c}0.030493 \\
(0.913904)\end{array}$ & 0.854498 & 0.828043 \\
\hline AUT & Upwards & $\begin{array}{l}32.40518 \\
(1.295752)\end{array}$ & $\begin{array}{l}-2.142506 \\
(-0.948419)\end{array}$ & $\begin{array}{c}0.051330 \\
(1.011825)\end{array}$ & 0.378121 & 0.265052 \\
\hline BEL & Downwards & $\begin{array}{l}-38.56085 \\
(-1.851958)\end{array}$ & $\begin{array}{l}5.308950 * * \\
(2.615751)\end{array}$ & $\begin{array}{l}-0.131785^{* *} \\
(-2.677372)\end{array}$ & 0.550391 & 0.468644 \\
\hline CAN & Downwards & $\begin{array}{l}-22.63661 * * * \\
(-2.243311)\end{array}$ & $\begin{array}{l}3.873565 * * * \\
(4.076439)\end{array}$ & $\begin{array}{l}-0.081868^{* * *} \\
(-3.68952)\end{array}$ & 0.938394 & 0.927193 \\
\hline DNK & Downwards & $\begin{array}{l}-130.6434 \\
(-2.525280)\end{array}$ & $\begin{array}{l}10.96458 \\
(2.881555)\end{array}$ & $\begin{array}{l}-0.205509 \\
(-2.953182)\end{array}$ & 0.582992 & 0.507173 \\
\hline FIN & Upwards & $\begin{array}{l}21.01166 \\
(0.955752)\end{array}$ & $\begin{array}{c}-0.831101 \\
(-0.390142)\end{array}$ & $\begin{array}{c}0.024292 \\
(0.45789)\end{array}$ & 0.302750 & 0.175978 \\
\hline FRA & Downwards & $\begin{array}{c}-2.632392 \\
(-0.108880)\end{array}$ & $\begin{array}{c}1.377545 \\
(0.578969)\end{array}$ & $\begin{array}{c}-0.038322 \\
(-0.657177)\end{array}$ & 0.613460 & 0.543179 \\
\hline DEU & Downwards & $\begin{array}{r}138.3095 * * * \\
(4.196044)\end{array}$ & $\begin{array}{l}-10.83267^{* * * *} \\
(-3.516506)\end{array}$ & $\begin{array}{l}0.232845^{* * *} \\
(3.241966)\end{array}$ & 0.936801 & 0.925311 \\
\hline GRC & Upwards & $\begin{array}{l}-20.33162 * * * \\
(-3.502620)\end{array}$ & $\begin{array}{l}5.666485^{* * * *} \\
(4.866364)\end{array}$ & $\begin{array}{l}-0.245186^{* * *} \\
(-4.237436)\end{array}$ & 0.963752 & 0.957161 \\
\hline ISL & Downwards & $\begin{array}{l}-77.06379 * * \\
(-2.78862)\end{array}$ & $\begin{array}{l}6.679580^{* * * *} \\
(3.269343)\end{array}$ & $\begin{array}{l}-0.124729 * * * \\
(-3.326760)\end{array}$ & 0.585287 & 0.509885 \\
\hline IRL & Downwards & $\begin{array}{l}5.488734^{* *} \\
(2.825733)\end{array}$ & $\begin{array}{l}0.993541^{* * *} \\
(4.932367)\end{array}$ & $\begin{array}{l}-0.020077^{* * *} \\
(-4.076325)\end{array}$ & 0.916828 & 0.901705 \\
\hline ITA & Upwards & $\begin{array}{l}20.70147 \\
(1.423277)\end{array}$ & $\begin{array}{l}-1.596125 \\
(-0.963007)\end{array}$ & $\begin{array}{c}0.053556 \\
(1.137567)\end{array}$ & 0.873783 & 0.850834 \\
\hline JPN & Downwards & $\begin{array}{l}-87.27719^{*} \\
(-1.992356)\end{array}$ & $\begin{array}{c}5.242161^{*} \\
(2.137457)\end{array}$ & $\begin{array}{c}-0.070249^{*} \\
(-2.049219)\end{array}$ & 0.724723 & 0.674673 \\
\hline LUX & Upwards & $\begin{array}{r}285.6577 * * \\
(2.807105)\end{array}$ & $\begin{array}{l}-12.93553^{*} \\
(-2.424703)\end{array}$ & $\begin{array}{l}0.156301^{*} \\
(2.27898)\end{array}$ & 0.695400 & 0.593867 \\
\hline NLD & Downwards & $\begin{array}{l}-49.51415^{* * *} \\
(-4.152276)\end{array}$ & $\begin{array}{l}6.288234 * * * \\
(5.532056)\end{array}$ & $\begin{array}{l}-0.154126^{* * *} \\
(-5.728593)\end{array}$ & 0.891220 & 0.871441 \\
\hline NZL & Upwards & $\begin{array}{l}51.06444 * * * \\
(5.525208)\end{array}$ & $\begin{array}{l}-5.513196^{* * *} \\
(-3.772111)\end{array}$ & $\begin{array}{l}0.226814 * * * \\
(3.946032)\end{array}$ & 0.754267 & 0.709589 \\
\hline NOR & Upwards & $\begin{array}{l}10.26701 \\
(1.105293)\end{array}$ & $\begin{array}{c}0.003849 \\
(0.006775)\end{array}$ & $\begin{array}{c}0.001170 \\
(0.136236)\end{array}$ & 0.531307 & 0.446090 \\
\hline PRT & Upwards & $\begin{array}{c}-0.742091 \\
(-0.060585)\end{array}$ & $\begin{array}{c}0.848519 \\
(0.323440)\end{array}$ & $\begin{array}{c}-0.000933 \\
(-0.006693)\end{array}$ & 0.925624 & 0.912101 \\
\hline ESP & Upwards & $\begin{array}{r}138.3095^{* * *} \\
(4.196044)\end{array}$ & $\begin{array}{l}-10.83267^{* * * *} \\
(-3.516506)\end{array}$ & $\begin{array}{l}0.232845^{* * *} \\
(3.241966)\end{array}$ & 0.936801 & 0.925311 \\
\hline SWE & Downwards & $\begin{array}{c}-0.307504 \\
(-0.031672)\end{array}$ & $\begin{array}{c}0.813270 \\
(1.035399)\end{array}$ & $\begin{array}{c}-0.018941 \\
(-1.200685)\end{array}$ & 0.752155 & 0.707093 \\
\hline CHE & Downwards & $\begin{array}{l}-151.3246 \\
(-1.489339)\end{array}$ & $\begin{array}{c}9.808735 \\
(1.578630)\end{array}$ & $\begin{array}{l}-0.151480 \\
(-1.596068)\end{array}$ & 0.497305 & 0.346496 \\
\hline UK & Downwards & $\begin{array}{c}26.26929 * * \\
(2.707568)\end{array}$ & $\begin{array}{c}-0.983528 \\
(-1.128769)\end{array}$ & $\begin{array}{c}0.015029 \\
(0.774713)\end{array}$ & 0.890297 & 0.881155 \\
\hline USA & Downwards & $\begin{array}{l}-13.12516 \\
(-0.929401)\end{array}$ & $\begin{array}{c}2.374616 \\
(2.639135)\end{array}$ & $\begin{array}{l}-0.037604 \\
(-2.640770)\end{array}$ & 0.388007 & 0.276735 \\
\hline
\end{tabular}

Type of curve means the degree number of the polynomial function.

Parentheses are $t$-statistic.

$* * *$ Significant at the $1 \%$ level, $* *$ significant at the $5 \%$ level, *significant at the $10 \%$ level. 
than 0.9 . Other countries only show some possibility of accepting EKC hypothesis; however, since the $R^{2}$ value is not high, other explanatory variables (such as technical development and trade indicators) are required to improve the $R^{2}$ value for curve fitting. In addition, Greece's data appear acceptable to EKC hypothesis; however, the curve is of increasing trend. Thus, further research is required in order to confirm that Greece's emissions will indeed decrease as predicted by the EKC hypothesis.

2. Fitting the linear curve and showing decreasing trend: Only United Kingdom and France. UK has shown an especially high linear fitting $R^{2}$ value. This result is consistent with the other opinions that UK is mostly likely to meet the Kyoto goal (European Environment Agency, 2006; Stagnaro, 2006).

3. Linear fitting and increasing trend: Italy, Portugal and Spain. The $R^{2}$ values for the three countries are fairly close to or over 0.9 , indicating that these countries will have great difficulties in meeting their Kyoto commitments. This result is also consistent with the assessment of other reports (European Environment Agency, 2006; Stagnaro, 2006).

4. Other curve-fitting result: Germany. It is surprising to see Germany in this category, as it is often thought of as the most favorable country to meet the Kyoto commitment and with the best emissions reduction results (European Environment Agency, 2006). Even though curve fitting does show some quadratic result, it is an inverted EKC result. Nonetheless, Germany's emissions did show a decreasing trend, and even though it did not conform with the EKC hypothesis, the actual emissions reduction efforts were not affected.

\section{Discussion}

\subsection{Revisit the EKC hypothesis}

The availability of emissions data for only the 1990-2003 period is the greatest limitation for this research. However, even with such limited data, we can still provide an initial conclusion as to the study on the validity of EKC hypothesis.

Statistically, most countries studied in this research did not show evidence to support the EKC hypothesis, which is consistent with a 1992 World Bank report that also showed little support for carbon dioxide emissions with the EKC curve. The econometric analysis of 38 industrialized countries also showed that they are unable to meet their commitments under the Kyoto Protocol by their efforts alone, and international cooperation is needed to close the gap.

In addition, the curve-fitting results also showed that for some countries, the coefficient between independent and dependent variables has high $t$-statistic, exhibiting its high explanatory power; both are closely correlated but the regression coefficient is not high. This result shows that when studying the EKC of these countries, external independent variables need to be added in order to obtain a better regression coefficient (Friedl and Getzner, 2003).

Furthermore, as many countries are already promoting international GHG emissions reduction projects, a lot of factors that are beyond the control of this model are being created, such as innovative technology, trade, energy taxes and the Clean Development Mechanism. Further research is needed in order to integrate and incorporate these additional factors.

At present, many countries are actively promoting international $\mathrm{CDM}$ projects in order to obtain the rights to sell or purchase GHG emissions quota. However, the price collapse of the European carbon market in 2006 may indicate that such an emissions trading mechanism could be creating a false impression that Kyoto goals are being met. In reality, it offers little help to mitigate the global warming trend and may actually create a different kind of carbon leakage. If international community truly wants to reduce the GHG emissions, the effectiveness of the existing international framework for emissions reduction needs to be reconsidered seriously, and the global cooperation mechanism also needs to be greatly enhanced.

\subsection{The myth of economic growth and GHG emissions decoupling}

The UNFCCC Secretariat has always advocated the concept that GHG emissions reduction will not affect economic growth (United Nations Framework Convention on Climate Change, 2004a, b), in order to encourage parties to the Convention to aggressively pursue GHG reduction actions. As late as in the UNFCCC COP-10 (2004) meeting, the former Executive Secretary of UNFCCC, Ms. Joke Waller-Hunter, mentioned during the COP-10 opening address that with the entry into force of the Convention 10 years ago, global energy intensity has decreased gradually, and especially that the GHG emissions growth rate is lower than the GDP grow rate. It can be inferred that the UNFCCC Secretariat's position implied the decoupling of economic growth and GHG emissions, and thus the EKC hypothesis is validated.

However, is it really reasonable to assume the decoupling of the economic growth and GHG emissions? This is a topic that was addressed by this research in two aspects. First, based on the observation of this research and the statistics from IEA (2005) and United Nations Framework Convention on Climate Change (2005), it can be demonstrated that the collapse of the EITs' economies in the early 1990s resulted in great decreases in global GHG emissions (Simeonova, 1997).

Secondly, of the 21 Annex II Parties studied in this research, 11 Parties showed a decreasing trend (a potential for decoupling to occur) and the US is one of them. Although US economic growth rate maybe higher than GHG emissions' growth rate, which is indicative of the decoupling effect, US emissions alone account for $25 \%$ of 
global emissions. Therefore, for a country like the US with such high emissions, merely showing that the economic growth rate is higher than the GHG emissions' growth rate is not enough to mask the fact that US emissions continue to grow in an alarming quantity and that its continuing growth means that a global emissions reduction is unlikely to be achieved. What is even worse is that lower emissions growth in the US maybe due to that fact that most consumer products in US are imported from foreign countries, which validates the pollution-haven hypothesis.

Therefore, when considering the decoupling of economic growth and GHG emissions, it is necessary to take into account the country's actual emissions and historical perspective. It is unrealistic to judge the performance of GHG emissions reduction efforts solely based on whether the decoupling has occurred or not.

\section{Conclusion}

This research observed that the economic development and GHG emissions in EITs exhibit a quasi-L-shape or hockey-stick-curve trend. Indeed, the EITs' economic collapse during the early 1990s created a lot of "hot air", which would help meet the emissions reduction targets under the first commitment period of the Kyoto Protocol. However, the EITs' further economic development may create more GHG emissions and result in great impact to the potential second and the third commitment periods for the Kyoto Protocol. At present, there are relatively few studies on the EIT's energy and economic structure, and further research may be required.

This research also found that for Annex II Parties with better economic status, most of them do not follow the EKC trend (only 7 out of 21 parties exhibit this trend). Based on the results of econometric analysis, UK and France show a linear decreasing trend in GHG emissions reduction, which is the classical example to demonstrate that continuous development of current economy can be accompanied by real GHG reductions. Even though the case of Germany did not validate the EKC hypotheses, it does show significant real reduction in GHG emissions.

The UNFCCC describes a situation in which economic growth rate may surpass the GHG emissions growth rate. However, based on findings of this research, the actual situation may not be as optimistic. In order for the Kyoto Protocol to achieve GHG emissions reduction and thus mitigate global climate change, merely relying on the efforts of scores of Annex I Parties is unlikely to achieve success.

As the Parties to the Kyoto Protocol are currently negotiating the framework for the second commitment period, it is the opinion of this research that the scope of the Parties required to limit GHG emissions should be expanded, in order to enhance the global efforts to reduce GHG emissions.

\section{References}

Dijkgraaf, E., Vollebergh, H.R.J., 2001. A note on testing for environmental Kuznets curves. Environmental Policy, Economic Reform and Endogenous Technology, Working Paper Series 7.

Duic, N., Juretic, F., Zeljkoc, M., Bogdan, Z., 2005. Croatia energy planning and Kyoto Protocol. Energy Policy 33, 1003-1010.

European Environment Agency, 2006. Greenhouse Gas Emission Trends and Projections in Europe 2006. Copenhagen, Denmark.

Friedl, B., Getzner, M., 2002. Environment and growth in a small open economy: an EKC case-study for Austrian $\mathrm{CO}_{2}$ emissions. Discussion Paper of the College of Business Administration, University of Klagenfurt, Austria.

Friedl, B., Getzner, M., 2003. Determinants of $\mathrm{CO}_{2}$ emissions in a small open economy. Ecological Economics 45, 133-148.

Grossman, G.M., Krueger, A.B., 1995. Economic growth and the environment. The Quarterly Journal of Economics 110 (2), 353-377.

Holtz-Eakin, D., Selden, T.M., 1995. Stoking the fires? $\mathrm{CO}_{2}$ emissions and economic growth. Journal of Public Economics 57, 85-101.

International Energy Agency, 2005. $\mathrm{CO}_{2}$ Emissions from Fuel Combustion 1971-2003. Paris, France.

Klepper, G., Peterson, S., 2002. Trading hot air-the influence of permit allocation rules, market power and the US withdrawal from the Kyoto Protocol. Kiel Working Paper no. 1133.

Klepper, G., Peterson, S., Springer, K., 2003. DART97: A description of the mmulti-regional, multi-sectoral trade model for the analysis of climate policies. Kiel Working Paper no. 1149.

Meadows, D.H., Meadows, D.L., Randers, J., Behrens, W.W., 1972. The Limits to Growth. Universe Books, New York.

Missfeldt, F., Haites, E., 2002. Analysis of a commitment period reserve at national and global levels. Climate Policy 2, 51-70.

Moomaw, W.R., Unruh, G.C., 1997. Are environmental Kuznets curves misleading us? The case of $\mathrm{CO}_{2}$ emissions. Environment and Development Economics 2, 451-463.

Munasinghe, M., 1995. Making economic growth more sustainable. Ecological Economics 15, 121-124.

Panayotou, T., 1997. Demystifying the environmental Kuznets curve: turning a black box into a policy tool. Environment and Development Economics 2, 465-484.

Panayotou, T., 2003. Economic growth and the environment. Presented at the Spring Seminar of the United Nations Economic Commission for Europe, Geneva.

Roberts, J.T., Grimes, P.E., 1997. Carbon intensity and economic development 1962-91: a brief exploration of the environmental Kuznets curve. World Development 25 (2), 191-198.

Roca, J., Alcantara, V., 2001. Energy intensity, $\mathrm{CO}_{2}$ emissions and the environmental Kuznets curve. The Spanish Case. Energy Policy. 29, $553-556$.

Schmalensee, R., Stoker, T.M., Judson, R.A., 1998. World carbon dioxide emission: 1950-2050. The Review of Economics and Statistics 80 (1), 85-101.

Selden, T.M., Song, D., 1994. Environmental quality and development: is there a Kuznets curve for air pollution emissions? Journal of Environmental Economics and Management 27, 147-162.

Shafik, N., 1994. Economic development and environmental quality: an econometric analysis. Oxford Economic Papers, New series 46, $757-773$

Simeonova, K., 1997. Polices and measures to address climate change in Central and Eastern European countries. Applied Energy 56, 445-461.

Stagnaro, C., 2006. EU may miss Kyoto targets despite EEA recommendations. Oil \& Gas Journal 104 (10), 24-26.

Stern, D.I., 1998. Progress on the environmental Kuznets curve? Environment and Development Economics 3, 173-196.

Sun, J.W., 1999. The nature of $\mathrm{CO}_{2}$ emission Kuznets curve. Energy Policy 27, 691-694. 
United Nations Framework Convention on Climate Change, 2004a. COP 10 Opening Statement by Ms. Joke Waller-Hunter Executive Secretary $\langle$ http://unfccc.int/files/meetings/cop_10/overview/application/pdf/cop10_ opening_waller-hunter.pdf $\rangle$.

United Nations Framework Convention on Climate Change, 2004b. Statement at the COP10 high-level segment by Ms. Joke Waller-Hunter
Executive Secretary 〈http://unfccc.int/files/secretariat/executive_ secretary/application/pdf/041215waller-hunter.pdf $\rangle$.

United Nations Framework Convention on Climate Change, 2005. Key GHG Data. Climate Change Secretariat, Bonn, Germany.

World Bank, 1992. World Bank Development Report 1992. Oxford University Press, New York. 